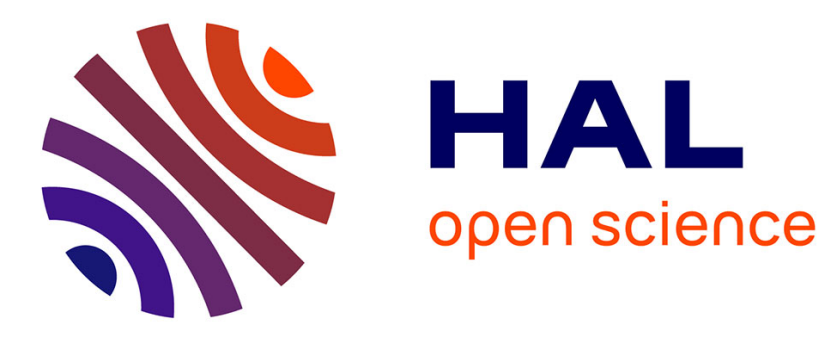

\title{
Chemoinformatics-Driven Design of New Physical Solvents for Selective CO 2 Absorption
}

Alexey Orlov, Daryna Yu. Demenko, Charles Bignaud, Alain Valtz, Gilles Marcou, Dragos Horvath, Christophe Coquelet, Alexandre Varnek, Frédérick de Meyer

\section{To cite this version:}

Alexey Orlov, Daryna Yu. Demenko, Charles Bignaud, Alain Valtz, Gilles Marcou, et al.. Chemoinformatics-Driven Design of New Physical Solvents for Selective CO 2 Absorption. Environmental Science and Technology, 2021, 55 (22), pp.15542-15553. 10.1021/acs.est.1c04092 . hal03435228

\section{HAL Id: hal-03435228 \\ https://hal.science/hal-03435228}

Submitted on 24 Nov 2021

HAL is a multi-disciplinary open access archive for the deposit and dissemination of scientific research documents, whether they are published or not. The documents may come from teaching and research institutions in France or abroad, or from public or private research centers.
L'archive ouverte pluridisciplinaire HAL, est destinée au dépôt et à la diffusion de documents scientifiques de niveau recherche, publiés ou non, émanant des établissements d'enseignement et de recherche français ou étrangers, des laboratoires publics ou privés. 


\section{Chemoinformatics-driven design of new physical}

3 Alexey A. Orlov ${ }^{\S}$, Daryna Yu. Demenko ${ }^{\S}$, Charles Bignaud ${ }^{\dagger}$, Alain Valtz ${ }^{\dagger}$, Gilles Marcou ${ }^{\S}$,

4 Dragos Horvath ${ }^{\S}$, Christophe Coquelett, Alexandre Varnek ${ }^{\xi^{*}}$, Frédérick de Meyer ${ }^{\dagger *}$.

$5 \S$ Laboratory of Chemoinformatics, Faculty of Chemistry, University of Strasbourg, Strasbourg,

$7 \dagger$ TotalEnergies S.E., Exploration Production, Development and Support to Operations,

8 Liquefied Natural Gas - Acid Gas Entity, CCUS R\&D Program, Paris, 92078 France

$9+$ MINES ParisTech, PSL University, Centre de thermodynamique des procédés (CTP), 35 rue St

11 Keywords: gas solubility, industrial gases, carbon dioxide, methane, nitrogen, hydrogen, carbon

12 monoxide, chemoinformatics, machine learning

13 
$\mathrm{CO}_{2}$ solubility data

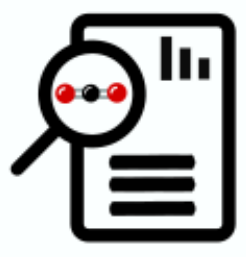

Mitigate $\mathrm{CO}_{2}$ emissions

Molecular descriptors

Virtual screening

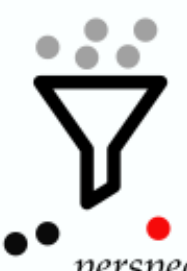

perspective solvent

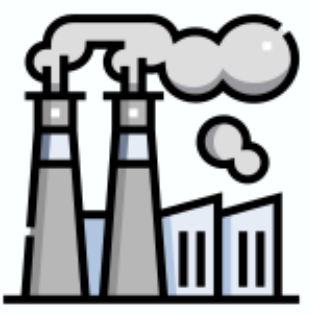

\begin{tabular}{|l|l|l|l|}
\hline$d_{1}$ & $d_{2}$ & $d_{3}$ & $d_{4}$ \\
\hline
\end{tabular}

Machine learning

$\chi_{\mathrm{CO}_{2}}=\mathrm{f}\left(\mathrm{d}_{1}, \mathrm{~d}_{2}, \ldots\right)$

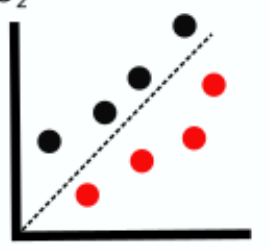

15 


\section{ABSTRACT}

17 The removal of $\mathrm{CO}_{2}$ from gases is an important industrial process in the transition to a low-

18 carbon economy. The use of selective physical (co-)solvents is especially perspective in cases

19 when the amount of $\mathrm{CO}_{2}$ is large as it enables one to lower the energy requirements for solvent

20 regeneration. However, only a few physical solvents have found industrial application and the

21 design of new ones can pave the way to more efficient gas treatment techniques. Experimental

22 screening of gas solubility is a labor-intensive process, and solubility modeling is a viable

23 strategy to reduce the number of solvents subject to experimental measurements. In this paper, a

24 chemoinformatics-based modeling workflow was applied to build a predictive model for the

25 solubility of $\mathrm{CO}_{2}$ and four other industrially important gases $\left(\mathrm{CO}, \mathrm{CH}_{4}, \mathrm{H}_{2}, \mathrm{~N}_{2}\right)$. A dataset

26 containing solubilities of gases in 280 solvents was collected from literature sources and

27 supplemented with the new data for six solvents measured in the present study. A modeling

28 workflow based on the usage of several state-of-the-art machine learning algorithms was applied

29 to establish quantitative structure-solubility relationships. The best models were used to perform

30 virtual screening of the industrially produced chemicals. It enabled the identification of

31 compounds with high predicted $\mathrm{CO}_{2}$ solubility and selectivity towards the other gases. The

32 prediction for one of the compounds - 4-Methylmorpholine was confirmed experimentally.

\section{SYNOPSIS STATEMENT}

34 Developing better solvents for selective $\mathrm{CO}_{2}$ capture is crucial for reaching net-zero emissions 35 targets. 
37 Global warming due to increasing levels of greenhouse gases $\mathrm{CO}_{2}$ and $\mathrm{CH}_{4}$ in the atmosphere

38 has become a major public issue. Several companies and countries have announced ambitious

39 plans to reach net zero $\mathrm{CO}_{2}$ emissions by 2050. According to the International Energy Agency,

40 Carbon Capture, Utilization or Storage (CCUS) will likely play an important role in achieving

41 this goal. ${ }^{1}$ Numerous materials for $\mathrm{CO}_{2}$ capturing from gases were suggested, including chemical

42 and physical solvents, zeolites, metal oxides, metal-organic frameworks, and membranes. ${ }^{2,3}$ The

43 applicability of a certain technology in each case depends on many factors, including the

44 concentrations of $\mathrm{CO}_{2}$ and of other components in the gas, the pressure of the gas feed, the

45 temperature, etc. In cases, wherein the partial pressure of $\mathrm{CO}_{2}$ in a gas mixture is sufficiently

46 large, physical solvents represent a perspective alternative to the conventionally used aqueous

47 amines mixtures because of the lower energy requirement. Indeed, a large part of a physical

48 solvent can be regenerated by pressure swing and air stripping, while the regeneration of

49 chemical solvents requires heating and steam stripping ${ }^{3,4}$ Pre-combustion $\mathrm{CO}_{2}$ capture is a key

50 example of a case with a $\mathrm{CO}_{2}$ partial pressure sufficiently high to use physical solvents. In a pre-

51 combustion process the feed (e.g. coal, natural gas, biomass, etc.) is converted into syngas $\left(\mathrm{H}_{2}\right.$

52 and $\mathrm{CO}$ ) via gasification, steam reforming, auto thermal reforming or partial oxidation and

53 subsequently the $\mathrm{CO}$ is further converted into $\mathrm{CO}_{2}$ and $\mathrm{H}_{2}$ via the water gas shift reaction.

54 Typical $\mathrm{CO}_{2}$ concentrations are in the range of 15 to $60 \mathrm{~mol} \%$ for a total pressure of 2 to $7 \mathrm{MPa}$,

55 thus, the $\mathrm{CO}_{2}$ can be captured with a physical solvent ${ }^{5}$. The other components are mainly $\mathrm{H}_{2}$, but

56 also $\mathrm{CO}, \mathrm{N}_{2}, \mathrm{CH}_{4}, \mathrm{H}_{2} \mathrm{O}$ (saturation). The composition strongly depends on the feedstock and on

57 the process. At the moment, only a limited number of physical solvents such as methanol

58 (Rectisol ${ }^{\circledR}$ process), propylene carbonate (Fluor ${ }^{\circledR}$ process), N-acetyl and N-formyl morpholines 
59 (Morphysorb ${ }^{\circledR}$ process), 1-methylpyrrolidin-2-one (Purisol ${ }^{\circledR}$ process), polyethylene glycol 60 ethers (Selexol ${ }^{\circledR}$ process), found application in the industrial $\mathrm{CO}_{2}$ capture processes. Physical 61 solvents are also often added to chemical solvents (so-called hybrid solvents), for example, to 62 increase the selectivity of absorption towards a specific gas component, to lower the regeneration 63 energy, etc. Examples are sulfolane (Sulfinol ${ }^{\circledR}$ process), thiodiglycol (Hysweet ${ }^{\circledR}$ process), etc.

64 The search for new physical (co-)solvents is thus an important task. ${ }^{6}$

65 New suitable solvents should satisfy many criteria, among which are a decent capacity to 66 absorb $\mathrm{CO}_{2}$, a competitive price, a low volatility (to avoid solvent losses), a low viscosity, etc.

67 Another very important criterium is the selectivity towards $\mathrm{CO}_{2}$ which should be high enough to 68 obtain a $\mathrm{CO}_{2}$ stream of acceptable purity for re-utilization or storage, and to avoid losses of 69 valuable chemicals like $\mathrm{CH}_{4}$. Depending on the source of the $\mathrm{CO}_{2}$, the selectivity criteria are 70 different. For the removal of $\mathrm{CO}_{2}$ from natural gas the co-absorption of mainly $\mathrm{CH}_{4}$, but also of $71 \mathrm{~N}_{2}$ and $\mathrm{H}_{2} \mathrm{O}$ and eventually $\mathrm{H}_{2} \mathrm{~S}$ should be limited. For a steam methane reformer (SMR), which

72 in a near future is likely to play a key role in the massive production of blue hydrogen from 73 natural gas, the absorption of $\mathrm{CO}_{2}$ with a high selectivity towards $\mathrm{H}_{2}$ is important ${ }^{7,8}$, but also 74 towards $\mathrm{CO}, \mathrm{H}_{2} \mathrm{O}, \mathrm{N}_{2}$ and $\mathrm{CH}_{4}{ }^{7,8}$. The $\mathrm{CO}_{2}$ present in flue gas from boilers should be removed 75 with a high selectivity towards $\mathrm{N}_{2}$, but the co-absorption of water and $\mathrm{SO}_{\mathrm{x}}, \mathrm{NO}_{\mathrm{x}}$ should be low 76 too.

77 Experimental screening of gas solubility is a time and labor-intensive process, and solubility 78 modeling is a viable strategy to reduce the costs of the required experiments. There were 79 numerous approaches suggested for modeling gas solubility in pure physical solvents. In the 80 work by Pirig et al. ${ }^{9}$ a five-parameter linear equation based on the experimentally measured 81 properties was used to model the solubility in 58 solvents. In the work by Li et al. ${ }^{10}$, artificial 
82 neural networks were used to model $\mathrm{CO}_{2}$ mole fraction solubility in 11 solvents (alcohols, ethers,

83 ketones) at different temperatures and pressures. Several structural features (number of C-H, O-

$84 \mathrm{H}, \mathrm{C}-\mathrm{O}, \mathrm{C}=\mathrm{O}$ bonds, number of rotatable bonds, etc.) and physical properties of the compounds

85 (density, dipole moment, etc.) were used as descriptors. It enabled achieving high precision of

86 predictions for certain types of physical solvents under varying experimental conditions.

87 Nonetheless, the major disadvantage of the modeling approaches based on experimentally

88 measured parameters - the limited number of compounds for which the parameters are available,

89 complicates their usage for large-scale virtual screening of solvent candidates.

90 Alternative strategies for modeling $\mathrm{CO}_{2}$ solubility, that require less preliminary knowledge of

91 the experimental properties, were also suggested. In the works of Li et al. ${ }^{11}$ and Shi et al. ${ }^{12}$

92 molecular simulations were used to predict $\mathrm{CO}_{2}$ solubility in nine and twenty-seven physical

93 solvents respectively. Although high predictive accuracy was achieved in both works, molecular

94 simulations are also not very convenient for the large-scale virtual screening, as they are time-

95 consuming and require significant computational resources. Alternatively, the conductor-like

96 screening model for real solvents (COSMO-RS), ${ }^{13}$ a method combining quantum chemical

97 calculations with statistical thermodynamics, was suggested to rapidly screen large sets of

98 various materials. In the work by Kim et al. ${ }^{14} \mathrm{CO}_{2}$ and $\mathrm{CH}_{4}$ Henry's law coefficients were

99 predicted by COSMO-RS for 63 common liquid solvents and 10 ionic liquids at $300 \mathrm{~K}$.

100 Unfortunately, there was no comparison of the predicted solubilities with the available

101 experimental data.

102 A pool of gas solubility data accumulated in scientific literature supports applying machine

103 learning for quantitative structure-solubility relationships (QSPR) modeling. In this approach

104 chemical structures of compounds are encoded as vectors of molecular descriptors and machine 
105 learning algorithms are then applied for modeling the property of interest. As compared to the

106 modeling based on the usage of experimentally determined parameters or resource-intensive

107 molecular simulations, this method allows efficient screening of large numbers of compounds.

108 To our knowledge, there was only one work related to QSPR modeling of $\mathrm{CO}_{2}$ solubility in

109 physical solvents published. ${ }^{15}$ In the paper of Gorji et al., ${ }^{15}$ Henry coefficients for 22 solvents

110 composed only of carbon, oxygen, and hydrogen elements at different temperatures were used to

111 build a multiple linear regression model with Dragon ${ }^{16}$ descriptors. Although good predictive

112 performance was achieved, the applicability domain (AD) of this model is limited to the specific

113 classes of compounds used for model building. Except for recent publications on $\mathrm{H}_{2} \mathrm{~S}$ solubility

114 modeling $^{17,18}$, to our knowledge there were no papers describing the application of the

115 chemoinformatics-driven methods for physical solubility modeling of the major components

116 encountered in natural gas treatment or in the pre-combustion $\mathrm{CO}_{2}$ capture process : carbon

117 dioxide $\left(\mathrm{CO}_{2}\right)$, methane $\left(\mathrm{CH}_{4}\right)$, carbon monoxide $(\mathrm{CO})$, hydrogen $\left(\mathrm{H}_{2}\right)$, and nitrogen $\left(\mathrm{N}_{2}\right)$. Hence,

118 the investigation of the perceptiveness of using chemoinformatics for the rational design of new

119 solvents for the absorption of $\mathrm{CO}_{2}$ and other industrial gases is an important task.

121 MATERIALS AND METHODS

122 Data collection and preprocessing

123 A dataset containing mole fraction solubility values $(\chi)$ for 280 liquid solvents at $298.15 \mathrm{~K}$ and

1241 atm was collected (Table S1, Supporting Information) from IUPAC reports ${ }^{19-23}$, scientific

125 literature ${ }^{24-75}$, and patents ${ }^{76,77}$. The mole fraction solubility for a binary (gas-liquid) system is 126 defined $^{19}$ as: 
$128 \mathrm{n}(\mathrm{g})$ - an amount of substance in a gas phase, $\mathrm{n}(\mathrm{l})$ - an amount of substance in a liquid phase.

129 Median values were then taken for the solvents associated to several reliable measurements of $130 \chi$ at the particular temperature. The final dataset used for modeling is present in Table S1 131 (Supporting Information). Extrapolation and interpolation of the data to $298.15 \mathrm{~K}$ were 132 performed assuming a linear variation of Henry's coefficients with temperature or by the 133 equations suggested in the IUPAC report or corresponding papers. The compounds that are 134 structural outliers with respect to the training set majority, comprising water, carbon disulfide, 135 octamethylcyclotetrasiloxane and hydrazines were not included to the dataset. These compounds 136 contain rare or unique fragments significantly affecting their gas-absorbing properties, and, 137 hence, confident predictions cannot be obtained for them by statistical modeling.

138 The collected mole fraction solubilities were converted to the Kuenen coefficients S using the 139 following formula ${ }^{78}$ :

$$
S=\frac{R \times T \times P}{M w} \times \frac{\chi}{1-\chi}
$$

$141 \mathrm{~S}$ - Kuenen coefficient $\left(\mathrm{m}^{3} \mathrm{~kg}^{-1}\right), \mathrm{R}-$ ideal gas constant $\left(8.314 \mathrm{~m}^{3} \mathrm{PaK}^{-1} \mathrm{~mol}^{-1}\right)$, $\mathrm{T}$ and $\mathrm{P}-$ 142 standard temperature and pressure $(273.15 \mathrm{~K}$ and $101.325 \mathrm{kPa}), \mathrm{Mw}-$ molecular weight of 143 compound $\left(\mathrm{kgmol}^{-1}\right), \chi$ - mole fraction solubility value.

144 The Kuenen coefficient is the volume of saturated gas reduced at $273.15 \mathrm{~K}$ and 1 atm pressure, 145 which is dissolved by unit mass of pure solvent at the temperature of measurement and partial 146 pressure of $1 \mathrm{~atm}$. This parameter is widely used in industrial applications, as it enables one to 
147 directly estimate the efficiency of the particular solvent related to its cost and dimensions of the

148 required industrial unit (design-capital expenses cost CAPEX). Here, Kuenen coefficients were

149 used for the data analysis and models interpretation.

150 The selectivity index SI was calculated using the following formula:

$$
S I=\frac{\chi_{\mathrm{CO} 2}}{\chi_{g a s}}
$$

152 SI - selectivity index, experimental or predicted $\chi_{\mathrm{CO} 2}$ and $\chi_{\text {gas }}-$ mole fraction solubilities of $153 \mathrm{CO}_{2}$ and other gases respectively.

154 All $\chi$ values were also transformed to a logarithmic scale, i.e. the negative value of the decimal 155 logarithm was taken (Figure S1).

$156 \quad$ Modeling

157 Standardization

158 All compound structures were standardized using in-house standardization procedures based

159 on KNIME, ${ }^{79}$ which included aromatization, stereochemistry depletion, etc.

160 Descriptors

161193 different ISIDA fragment descriptor sets were generated using the Fragmentor17

162 software. ${ }^{80,81}$ ISIDA fragments represent either sequences (the shortest topological paths with an

163 explicit representation of all atoms and bonds), atom-centered fragments (all connected atoms to

164 a certain topological distance), or triplets (all the possible combinations of 3 atoms in a graph

165 with the topological distance between each pair indicated). The number of fragments in each set 
166 varied from 30-40 (for short sequences of atoms/bonds) to 400-1200 (for long sequences up to 6

167 atoms) for different gases.

168 Quantum chemical descriptors resulted from DFT calculations in the gas phase, with model 169 wB97X-D 6-31G* performed with the Spartan 18.0 program $^{82}$. Default QSAR descriptors 170 available in Spartan including energy, dipole moment, $\mathrm{E}_{\mathrm{HOMO}}$, and $\mathrm{E}_{\mathrm{LUMO}}$ were calculated.

171 Machine learning algorithms

172 Random forest (RF): RF algorithm ${ }^{83}$ implemented in sci-kit learn library (v. 0.22.1) ${ }^{84,85}$ was

173 used. The following hyperparameters were tuning during optimization (grid search): number of 174 trees $(100,300,1000)$, number of features (all features, one-third of all features, $\log _{2}$ of the 175 number of features), the maximum depth of the tree $(5,10$, full tree), bootstrapping (with and 176 without the usage of bootstrap samples for building the tree).

177 XGBoost (XGB): XGBoost algorithm ${ }^{86}$ as implemented in XGBoost python module (v.1.2.0 $)^{87}$ 178 was used. The following hyperparameters were tuning during optimization (grid search): number 179 of trees $(50,100,300,500)$, number of features (all features, $70 \%$ of all features), number of 180 samples (all samples, $70 \%$ of all samples), the maximum depth of the tree $(3,5,10)$, learning rate $181(0.3,0.1,0.5,0.05)$, the minimum sum of instance weight needed in a node $(1,5,10)$. All other 182 parameters were left as default.

183 Support vector regression (SVR): SVR algorithm ${ }^{88}$ implemented in sci-kit learn library (v. 184 0.22.1), was used. The descriptors were scaled to the $[0,1]$ range before applying the algorithm. 185 The following hyperparameters were tuning during optimization (grid search): kernel (linear, rbf, 
186 poly, sigmoid), kernel coefficient $(1,0.1,0.01,0.001,0.0001)$, regularization parameter $(0.1,1$,

$18710,100,1000)$.

188 Model validation workflow

189 The modeling workflow was implemented using sci-kit learn library (v. 0.22.1) in python 3.7

190 scripting language. Identical modeling workflows were used for solubility modeling (expressed

191 as $-\lg \chi)$ of all gases. At the first stage of the modeling, a machine learning algorithm: RF, SVR

192 and XGB were tested in 5-fold cross-validation, which was repeated 5 times (Figure S2). For

193 each descriptor set, the model's measures of performance were calculated and several models

194 with a coefficient of determination $\mathrm{Q}_{\mathrm{CV}}^{2} \geq 0.7$ were selected for consensus modeling.

195 The following equations were used to calculate the measures of the model's performance in

196 cross-validation:

$$
Q_{C V}^{2}=\frac{\sum_{j=1}^{5}\left(1-\frac{\sum_{i=1}^{n}\left(y_{i, e x p}-y_{i, p r e d}\right)^{2}}{\sum_{i=1}^{n}\left(y_{i, e x p}-\bar{y}\right)^{2}}\right)}{5}
$$

$$
R M S E_{C V}=\frac{\sum_{j=1}^{5} \sqrt{\sum_{i=1}^{n} \frac{\left(y_{i, \text { exp }}-y_{i, p r e d}\right)^{2}}{n}}}{5}
$$

$$
M A E_{C V}=\frac{\sum_{j=1}^{5} \sum_{i=1}^{n} \frac{\left|y_{i, e x p}-y_{i, p r e d}\right|}{n}}{5}
$$

200 Above, $\mathrm{n}$ is the number of compounds in the entire learning set, $\mathrm{y}_{\mathrm{i}, \text { exp }}, \mathrm{y}_{\mathrm{i}, \text { pred }}$ experimental and

201 values predicted in 5-fold cross-validation for compound i from the learning set, $\mathrm{j}$ is the index of 202 the repetition of the 5-fold cross-validation procedure. For each measure of the model's 203 performance, the standard deviation over 5 repetitions was calculated. 
204 Each of the selected models was then associated with an Applicability Domain (AD), defined

205 as a bounding box. ${ }^{89}$ Hence, the pool of selected models extracted from the given data set was

206 used as a consensus predictor, returning for each input solvent candidate a mean value of

207 solubility estimates and its standard deviation, taken over the predictions returned by each model

208 in the pool, if the compounds appeared outside $\mathrm{AD}$ of all the models, or, alternatively, over the

209 predictions returned by only those models having the candidate within their AD.

210 Outlying data points were defined as the data points for which absolute errors $(|\chi \exp -\chi \operatorname{pred}|)$

211 from cross-validation were larger than $2 \times \mathrm{RMSE}_{\mathrm{CV}}$ threshold.

\section{$212 \quad$ Y-randomization test}

213 The absence of chance correlation was checked through the Y-randomization procedure. Y-

214 randomization test was performed in the following way: $-\lg \chi$ values ( $y$ values) were shuffled,

215 surrogate models from the cross-validation were built using shuffled values and the values from

216 the corresponding cross-validation test set were calculated. This procedure was repeated 100

217 times for each fold and the maximum values of the coefficient of determination were compared 218 with the coefficient of determination obtained for the original $-\lg \chi$ values.

$219 \quad$ Virtual screening

220 An in-house dataset comprising 4,082 industrially produced compounds and their 221 structural analogs was screened in the following way. Only structures containing the same atoms

$222(\mathrm{C}, \mathrm{H}, \mathrm{N}, \mathrm{O}, \mathrm{S}, \mathrm{P}$, halogens) as in the learning set were kept. All structures were standardized and 223 ISIDA descriptors were calculated for them as described above. Individual ISIDA models 224 refitted to the entire dataset with the hyperparameters selected in the cross-validation were used 
225 to compose the final consensus model as described above. Then, predictions were made using the

226 ISIDA consensus model. Only compounds that were inside the applicability domain defined as

227 bounding box for at least three ISIDA fragment types were considered.

228 Software implementation

229 The developed model was implemented into the ISIDA-Predictor software. ${ }^{81}$

$230 \quad$ Experimental measurement of $\mathrm{CO}_{2}$ solubility

231 A "static-synthetic" technique based on a closed-circuit method"90-92 was used for the 232 determination of $\mathrm{CO}_{2}$ solubility in the solvents. In this method, which is explained in detail in the

233 supplementary information (Text S1, Figures S3, S4), the system pressure is measured at 234 constant temperature for different overall compositions. To determine the global compositions, 235 the quantities of pure substances charged into the stirred equilibrium cell, which is evacuated and 236 placed in a thermostatic liquid bath, need to be known precisely. The purified and degassed 237 solvents are charged into the cell as compressed liquids using thermostatted piston injectors. 238 Then, the gas is added stepwise as a liquefied gas using the same injection pumps or as a gaseous 239 component using a thermo-regulated gas bomb. Knowing the pressure, temperature, and volume 240 of the gas bomb, the amount of gas inside the bomb can be calculated using correlated PvT data 241 of the gas. Thus, the injected amount of gas can be obtained from the pressure difference in the 242 bomb before and after each injection.

243 Since only temperature, pressure, total loadings, gas-liquid interface level and total volumes 244 are measured, the compositions of the coexisting phases need to be determined by the evaluation 245 of the raw data. From the known amount of solvent, the liquid phase volume is determined using 
246 precise information about the density of the liquid solution inside the equilibrium chamber. From

247 the total volume of the cell, the remaining gas phase volume can be calculated precisely (see

248 supplementary information). At given equilibrium conditions (temperature, gas phase volume,

249 and gas pressure) the amounts of gas in the gas phase and thus, also in the liquid phase are

250 obtained. In this approach, several effects influence the resulting liquid phase compositions.

251 These effects are the small amounts of solvents in the gas phase, the compressibility of the

252 solvent under the gas pressure, the partial molar volume of the dissolved gas and the solvent

253 activity coefficient. All effects are considered in an isothermal and isochoric algorithm by

254 solving the mass and volume balances.

255 The partial pressure is obtained during the iterative procedure:

$$
\text { Pgas }=\text { Psys }- \text { Psolvent }
$$

257 where Pgas - partial pressure of the acid gas in the system, Psys - total pressure in the system,

258 Psolvent - partial pressure of a solvent vapour. This equation is valid at low pressure and in the

259 absence of chemical reactions in the gas phase. The method to calculate the uncertainty of the

260 measured experimental data is explained in the supplementary information. The uncertainty of

261 the measured $\mathrm{CO}_{2}$ solubility at $1 \mathrm{~atm}$. is equal or lower than $1 \%$.

\section{RESULTS AND DISCUSSION}

263 Data collection, preprocessing and analysis

264 IUPAC reports on gas solubilities in non-aqueous solvents contain to our knowledge the most 265 complete and carefully analyzed publicly available data on gas solubility. The data from these 266 reports were used to compose the "cores" of our datasets. As the largest number of data points 
267 for various solvents was available at $298.15 \mathrm{~K}$ and $1 \mathrm{~atm}$, the data at this temperature and

268 pressure was chosen for modeling. Since the mole fraction values can vary significantly

269 depending on the experimental methods being used, we chose only the data points which were

270 considered as the most reliable by IUPAC's or Total's experts. Data from recent publications

271 either at $298.15 \mathrm{~K}$ or obtained by extrapolation or interpolation of the data measured at close

272 temperatures were also added to the dataset.

273 Besides the data collected from IUPAC reports and literature, data points for six compounds,

274 hexametapol (HMPA), 1,3-Dimethylimidazolidin-2-one (DMI), thiodiglycol (TDG), and three

275 tertiary amines 2-[2-hydroxyethyl(methyl)amino]ethanol (MDEA), 2-[ethyl(2-

276 hydroxyethyl)amino]ethanol (EDEA), and 2-[2-(diethylamino)ethoxy]ethanol (DEAE-EO) were

277 measured experimentally and added to the dataset (Figure 1a; Table S1). The choice of the

278 solvents was motivated by their wide application in industrial processes and the absence of

279 consistent data at $298.15 \mathrm{~K}$ for them in the literature. TDG is employed in a commercial mixed

280 chemical/physical solvent formulation for sour gas treating (HySWEET technology) developed

281 by TotalEnergies S.E. ${ }^{93}$ HMPA and DMI are being used as solvents for gases, polymers, and in

282 organic synthesis. Aqueous amines are used as chemical solvents, and only little is known about

283 the physical solubility of gases in pure amines. One of the few examples is MDEA, which, in an

284 aqueous solution, is commonly used for industrial gas treatment, and for which the $\mathrm{CO}_{2}$ mole

285 fraction solubility can be estimated from Skylogianni. ${ }^{94}$ The value is extremely high $(\sim 0.04$ at 1

286 atm and $313 \mathrm{~K}$ ) as compared to other physical solvents (see below). Hence, considering the

287 growing interest in water-lean solvents ${ }^{95}$, including the ones based on pure amines ${ }^{96}$, we have

288 chosen three industrial amines (MDEA, EDEA, DEAE-EO) for the experimental assessment of

$289 \mathrm{CO}_{2}$ physical solubility. 
290 All the solvents showed close to linear variation of mole fraction solubility vs partial pressure 291 of the gas in the pressure range 0-2 atm (Figure 1a). Estimated mole fraction solubilities for TDG 292 and DMI $(0.0041 ; 0.0150)$ are in good agreement with the data that can be obtained by 293 extrapolation from recent publications. ${ }^{27,97}$ On the contrary, $\mathrm{CO}_{2}$ mole fraction solubility in 294 HMPA (0.024) is lower, than the one suggested by IUPAC's expert ${ }^{19}(0.031)$, but is close to the 295 one obtained by Schay et al. ${ }^{19}(0.028)$. The mole fractions values in MDEA (0.1) and EDEA 296 (0.08) are remarkably high and in agreement with the aforementioned data for MDEA from the 297 Skylogianni et al. obtained at higher temperatures. ${ }^{94}$ At the same time, the $\mathrm{CO}_{2}$ solubility in 298 DEAE-EO is much lower (0.02) and is the same as in two other tertiary amines present in the 299 dataset: triethylamine (0.02) and perfluorotributylamine (0.02).

300 The high $\mathrm{CO}_{2}$ solubility in pure MDEA and EDEA triggers the question whether the 301 absorption is purely physical. It is commonly reported in the literature that, contrary to primary 302 and secondary amines, tertiary amines cannot chemically absorb $\mathrm{CO}_{2}$ in the absence of water ${ }^{98,99}$ 303 (we have verified that no water was present in the solvent in the experiments performed in the 304 present paper). This view has been challenged by Maddox ${ }^{100}$ and more recently by Heldebrandt 305 et al. ${ }^{101,102}$ who studied the reaction of $\mathrm{CO}_{2}$ with anhydrous tertiary amines. Both conclude that 306 reversible Lewis acid-base adducts are formed at high pressure (note that in this work we 307 compare solubilities at low pressure, $1 \mathrm{~atm}$.). Heldebrandt ${ }^{101}$ suggests that the difference in 308 absorption capacity between pure amines can be explained by solvent polarity effects. Either 309 way, anhydrous tertiary amines do absorb less $\mathrm{CO}_{2}$ than aqueous tertiary amines, but some still 310 absorb significant amounts of $\mathrm{CO}_{2}$. 
a

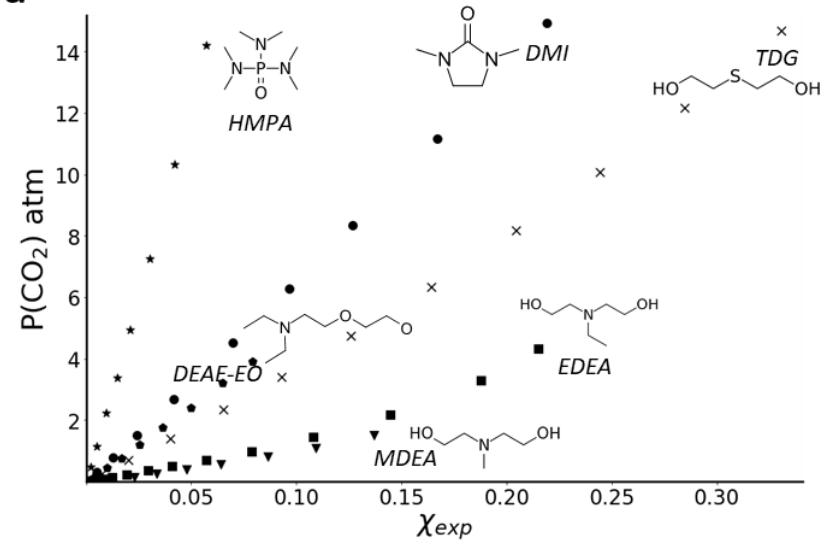

b

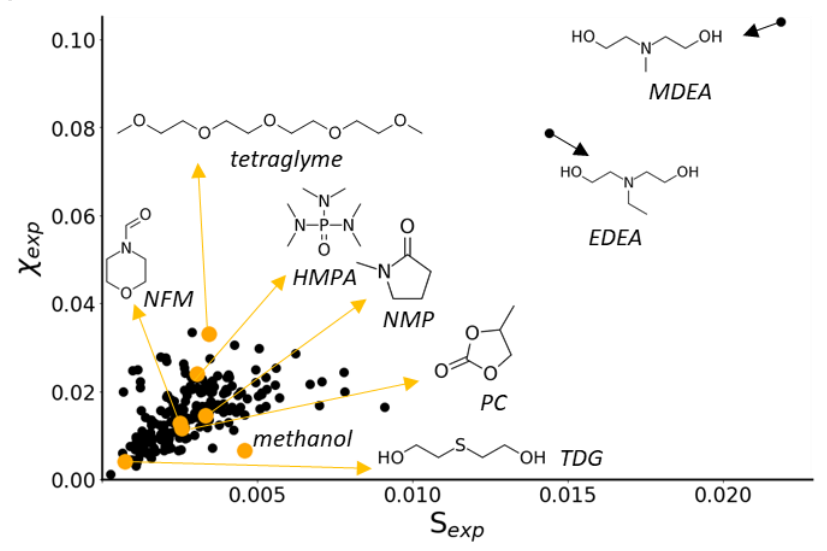

Figure 1. (a) Variation of mole fraction with partial pressure for $\mathrm{CO}_{2}$ in TDG $(\times)$, DMI ( $\star$ ), HMPA (•), MDEA

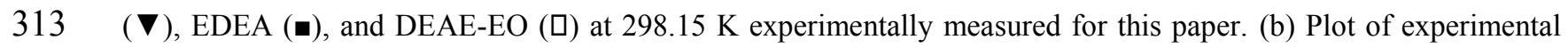

314 molecular fraction values $\left(\chi_{\text {exp }}\right)$ vs Kuenen coefficients $\left(\mathrm{S}_{\text {exp }}\right)$ at $298.15 \mathrm{~K}$ and 1 atm for $\mathrm{CO}_{2}$.

315 There were 211 mole fraction solubility values collected for $\mathrm{CO}_{2}$. The largest mole fraction

$316 \mathrm{CO}_{2}$ solubility was for tertiary amines MDEA and EDEA (Figure 1b). Among other classes of

317 compounds with large $\mathrm{CO}_{2}$ solubility were phosphoric acid esters, long chain ethers, and esters.

318 To estimate the efficiency of a solvent related to its cost and dimensions of the required

319 industrial unit, mole fractions were converted to Kuenen coefficients. MDEA and EDEA also

320 have the largest Kuenen coefficients. By contrast to the trend observed for mole fractions, the

321 largest Kuenen coefficient values in other compound classes were for small polar compounds:

322 nitriles, ketones (acetone, butan-2-one), tetrahydrofuran (THF). Notably, the solvents, which are

323 used in industrial gas treatment processes are not among the best ones in terms of $\mathrm{CO}_{2}$ solubility

324 (Figure 1b).

325 Other gases are less studied as compared to $\mathrm{CO}_{2}$. There were less than 105 mole fraction

326 solubility values collected for each of other gases $\left(\mathrm{N}_{2}, \mathrm{H}_{2}, \mathrm{CO}, \mathrm{CH}_{4}\right)$. It is worth noting, that

327 polar $\mathrm{CO}$ and non-polar $\mathrm{CH}_{4}, \mathrm{~N}_{2}, \mathrm{H}_{2}$ showed similar solubility trends. The largest values were 
328 for non-polar compounds, including perfluorated alkanes, and long-chain n-alkanes (Figure S5).

329 The minimal $\chi$ values were for polar solvents, such as methanol, $N, N$-dimethylformamide

330 (DMF).

331 The collected experimental data were used to analyze the trends in the selectivity of $\mathrm{CO}_{2}$ 332 absorption towards other gases (Figure S6). The only industrial solvent for which the data were 333 available for all the solvents is methanol, which is not selective at $298.15 \mathrm{~K}$ and 1 atm. The 334 industrially used solvents were among the best ones in terms of the $\mathrm{CO}_{2} / \mathrm{CH}_{4}$ selectivity. The 335 highest selectivity index (SIexp) was for dimethyl sulfoxide (DMSO, SIexp=24) and N-formyl 336 morpholine (NFM, SIexp=21). Among other most selective solvents were industrially used 337 propylene carbonate (PC) and N-Methyl-2-pyrrolidone (NMP). The large selectivity stems from 338 the extremely low solubility of $\mathrm{CH}_{4}$ in these solvents. The same observation was made for all 339 other gases: the most selective are the polar solvents, such as DMF, 1,4-dioxane, DMSO, etc. 340 (Figure 1b, Figures S3-S4).

341 Quantitative structure solubility relationships

342 Application of the machine learning allowed one to establish quantitative structure343 solubility relationships. Reasonable predictive accuracy was achieved in the repeated cross344 validation procedure for all the gases (Table 1). None of the models has shown chance 345 correlation in the $y$-scrambling procedure.

346 Table 1. Performance estimation for modeling of mole fraction solubility expressed as $-\lg \chi$.

\begin{tabular}{|c|c|c|c|c|}
\hline Gas & ISIDA consensus models & $\mathrm{Q}^{2}{ }_{\mathrm{CV}}$ & $\mathrm{RMSE}_{\mathrm{CV}}$ & $\mathrm{MAE}_{\mathrm{CV}}$ \\
\hline $\mathrm{CO}_{2}$ & $20 \mathrm{RF}, 17$ XGBoost & $0.71 \pm 0.01$ & $0.12 \pm 0.01$ & $0.08 \pm 0.01$ \\
\hline
\end{tabular}




\begin{tabular}{|c|c|c|c|c|}
\hline $\mathrm{CH}_{4}$ & 9 SVR, 15 XGBoost & $0.77 \pm 0.02$ & $0.15 \pm 0.01$ & $0.10 \pm 0.01$ \\
\hline $\mathrm{CO}$ & 5 SVR, 8 XGBoost & $0.78 \pm 0.03$ & $0.12 \pm 0.01$ & $0.09 \pm 0.01$ \\
\hline $\mathrm{H}_{2}$ & 2 RF, 3 SVR, 23 XGBoost & $0.77 \pm 0.04$ & $0.15 \pm 0.01$ & $0.10 \pm 0.01$ \\
\hline $\mathrm{N}_{2}$ & 9 SVR, 12 XGBoost & $0.75 \pm 0.06$ & $0.17 \pm 0.01$ & $0.11 \pm 0.01$ \\
\hline
\end{tabular}

348 Since the collected datasets are small, the presence of compounds containing rare fragments, or 349 compounds with noise in the experimental data lead to unstable modeling results. Several 350 compounds, which were systematically mispredicted (the absolute error $>0.7 \log$ units) in the 351 cross-validation procedure were removed: dodecanal and dodecene for the $\mathrm{H}_{2}$ model, and 352 dimethyl ether and dodecanal for the $\mathrm{CO}$ model. The values for all these compounds are 353 significantly different from their close structural analogs. They were obtained by interpolation 354 and additional experimental confirmation is required to assess whether the values are reliable. 355 After the removal of outliers, the models with reasonable figures of merit were obtained for each 356 gas (Table 1). The lowest mean absolute error $\left(\mathrm{MAE} \mathrm{CV}_{\mathrm{V}}\right)$ was for the $\mathrm{CO}_{2}$ model, which is based 357 on the largest pool of data. Note, that $\mathrm{MAE}_{\mathrm{CV}}$ is close to the variance in the experimental data.

358 For example, the standard deviation for propylene carbonate based on IUPAC's data ${ }^{19}$ and the 359 recently published data ${ }^{36}$ can be estimated as $0.05 \log$ units.

360 To check if some other descriptor types can lead to significantly better results, we calculated 361 quantum chemical descriptors using Spartan software. The results of modeling were on average 362 comparable to those obtained by the usage of ISIDA fragments (Table S2). Considering the 363 advantages of ISIDA fragments, i.e. speed of calculation and intuitive interpretation of structure364 property relationships, we further focused on this descriptor type. 
365 For each model, the compounds for which absolute errors were larger than $2 \times \mathrm{RMSE}_{\mathrm{CV}}$

366 threshold were analyzed (Figure 2, Table S3). These compounds either contain rare fragments or

367 can be considered as "solubility cliffs": small changes in structure (e.g. replacement of hydrogen

368 atom by methyl group) lead to large changes in solubility (see Figure S7 and discussion below).

369 For example, hexafluorobenzene - the only polyhalogenated aromatic compound and MDEA -

370 one of few representatives of alkanolamines in the dataset were among the compounds with the

371 largest errors for the $\mathrm{CO}_{2}$ model. The datasets for the gases are rather chemically diverse. Many

372 compounds containing rare fragments appear outside $\mathrm{AD}$ of the models in the cross-validation.

373 There were $15 \%$ of compounds appearing to be outside $\mathrm{AD}$ in the cross-validation for $\mathrm{CO}_{2}$,

374 while about $20-25 \%$ of compounds were outside $\mathrm{AD}$ for other gases. The presence of compounds

375 with rare fragments leads to high variance of predictions in the cross-validation. From the

376 learning curve (Figure S8), one can see that adding data improves the performance on the

377 validation sets, and, therefore, decreases the gap between prediction accuracy on validation and

378 training sets. Hence, further accumulation of the experimental data on gas solubility organic

379 solvents is required for building more robust models with enlarged applicability domains and the

380 extended range of temperature and pressure values. 

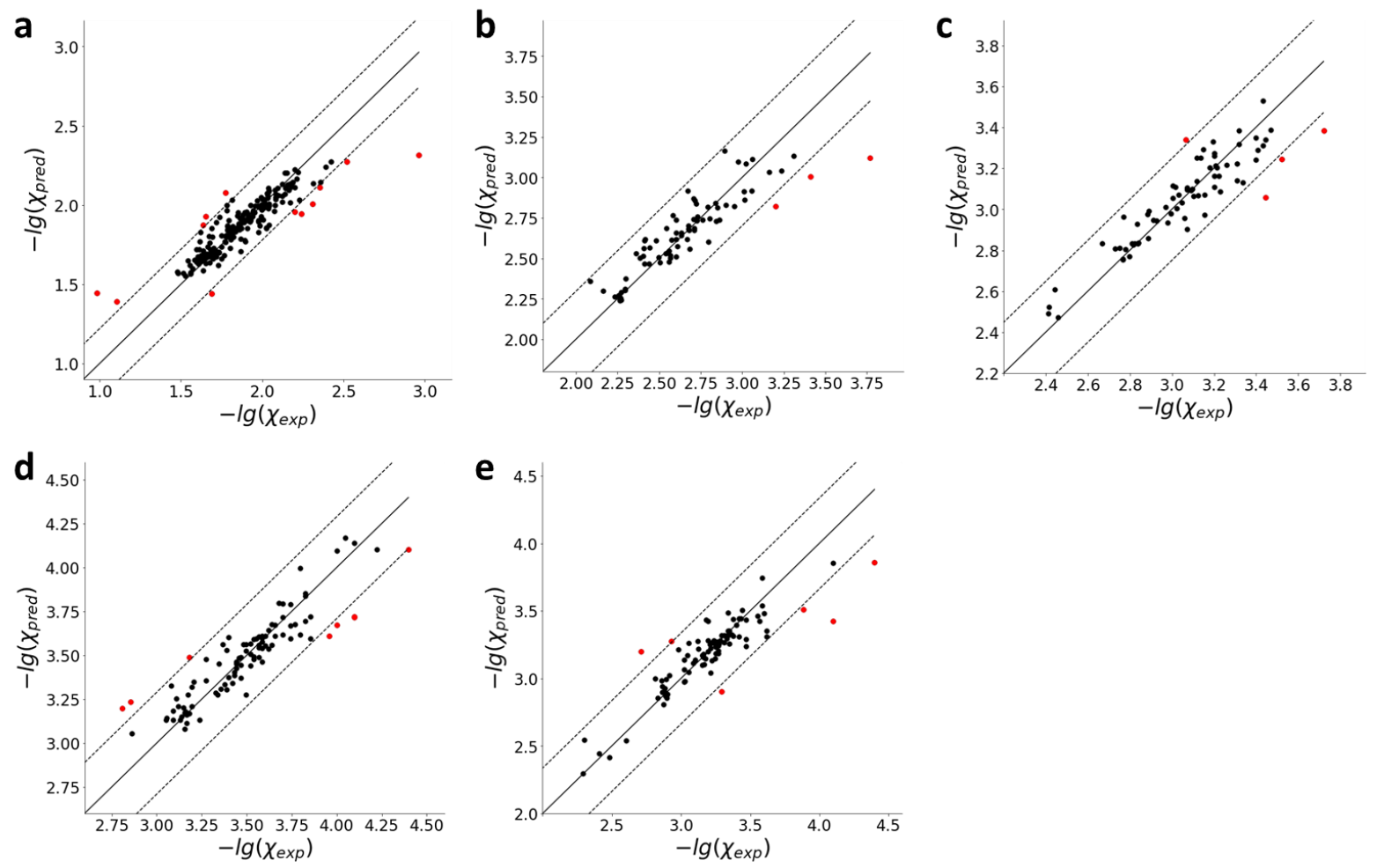

Figure 2. Plot of predicted $\left(-\lg \chi_{\text {pred }}\right)$ vs experimental $\left(-\lg \chi_{\text {exp }}\right)$ values for ISIDA consensus model in crossvalidation procedure for $\mathrm{CO}_{2}(\mathrm{a}), \mathrm{CH}_{4}(\mathrm{~b}), \mathrm{CO}(\mathrm{c}), \mathrm{H}_{2}(\mathrm{~d}), \mathrm{N}_{2}$ (e). The predicted values are calculated as an average

384 of 5 folds. Compounds for which absolute errors were larger than $2 \times \mathrm{RMSE}_{\mathrm{CV}}$ are shown in red. Dash lines indicate $385 \pm 2 \times \mathrm{RMSE}_{\mathrm{CV}}$ threshold.

In contrast to the above examples, solubility of $\mathrm{CO}_{2}$ in alcohols, glycols and ethers was

388 systematically studied. Yet, one of the largest absolute errors were for glycols (glycerol, ethane-

389 1,2-diol), which is related to a sharp change in solubility with the replacement of -OH group to -

$390 \mathrm{OCH}_{3}$ (Figure S7). For example, the mole fraction solubility in glycerol is more than three-time

391 smaller, than the solubility in its closest structural analog - propylene glycol (PG). At the same

392 time solubility in another structural analog - diethylene glycol (DEG), containing the same

393 number of carbon and oxygen atoms as glycerol, is six time higher. This phenomenon can be 
394 explained by considering forces driving the process of gas dissolution. The mechanistic 395 interpretation of this process assumes the formation of a cavity capable of accommodating a gas 396 molecule by breaking solvent-solvent bonds and introduction and fixation of a gas molecule in

397 this cavity due to gas-solvent interactions. Hence, solubility of gases in liquids depends upon two 398 types of interactions: gas-solvent and solvent-solvent. ${ }^{103,104}$ Strong gas-solvent and weak solvent399 solvent interactions lead to greater solubility. In line with that, $\mathrm{CO}_{2}$ solubility in glycols and their 400 ethers follows the cohesive energy density values trend: the solubility is increasing from glycerol

401 to DEG with the decreasing cohesive energy density (glycerol: $1142 \mathrm{MPa}$; DEG: $615 \mathrm{MPa}$ ). ${ }^{105}$

402 However, the cohesive energy density is not the only factor affecting the solubility of $\mathrm{CO}_{2}$. 403 Although carbon dioxide is nonpolar, its appreciable polarizability and ability to accept hydrogen 404 bonds from suitable donor solvents ${ }^{106}$ makes structure solubility landscape more complex. For 405 example, $\mathrm{CO}_{2}$ solubility is lower in hexane than in dimethyl ether of ethylene glycol (DMEG), 406 while the cohesive energy density of DMEG is higher than that of hexane (DMEG: $317 \mathrm{MPa}$; 407 hexane: $222 \mathrm{MPa})^{105,107}$. Thus, the interplay between cohesive energy density and solvent- $\mathrm{CO}_{2}$ 408 interactions should be taken into account in the process of the design of new solvents.

$409 \quad$ Virtual screening

410 To find new solvents with high $\mathrm{CO}_{2}$ solubility and high selectivity towards other gases, we

411 performed the virtual screening of the in-house library of industrially produced chemicals and 412 their close structural analogs comprising more than 4,000 chemicals (Figure S9). It is worth 413 noting that the experimentally measured physico-chemical properties such as melting and boiling 414 points, density, flash points, etc. were available only for a small fraction of the dataset and thus, 415 we did not check if the compounds possess plausible values of properties at $298.15 \mathrm{~K}$ and $1 \mathrm{~atm}$. 416 Most of the screened compounds (87\%) appeared to be inside $\mathrm{AD}$ of the $\mathrm{CO}_{2}$ model. There were 
417 numerous compounds found with high predicted $\mathrm{CO}_{2}$ mole fractions values and Kuenen 418 coefficients, several of which were superior to the existing industrially used solvents (Figure 3a).

419 Among the best $\mathrm{CO}_{2}$ solvents according to mole fraction solubilities were tertiary amines and 420 long-chain esters (e.g., dioctyl adipate, $\chi_{\text {pred }}=0.27$ ), while the largest Kuenen coefficients were 421 for tertiary amines and the close structural analogs of the compounds with the largest Kuenen 422 coefficients from the learning set: ethers (e.g. ethyl methyl ether, $\mathrm{S}_{\text {pred }}=0.0068$ ), ketones (e.g. 423 methoxyacetone, $\mathrm{S}_{\text {pred }}=0.0053$ ) and nitriles (e.g. butyronitrile, $\mathrm{S}_{\text {pred }}=0.0052$ ). One of the 424 tertiary amines with the largest Kuenen coefficient $\left(\mathrm{S}_{\text {pred }}=0.0054\right)-4$-Methylmorpholine 425 (NMM) was selected for the experimental measurement of solubility. NMM showed linear 426 variation of mole fraction solubility vs partial pressure of the gas in the pressure range indicating 427 pure physical solubility (Figure $3 b)$. The experimental mole fraction solubility (0.26) matched 428 the predicted one $(0.24)$ well. The $\mathrm{CO}_{2}$ solubility in $\mathrm{NMM}$ is appreciably higher than in 429 industrially used NFM, which instead of a tertiary amine group contains an amide group. We 430 have measured the dynamic viscosity of NMM: $0,92 \mathrm{cP}$ at $20^{\circ} \mathrm{C}$. The dynamic viscosity of water 431 at $20^{\circ} \mathrm{C}$ is $1 \mathrm{cP}$. The viscosity of $\mathrm{NMM}$ is thus comparable to water. NMM is much less viscous 432 than e.g. pure MDEA $\left(100 \mathrm{cP}\right.$ at $\left.20{ }^{\circ} \mathrm{C}\right)$ or pure EDEA $\left(90 \mathrm{cP}\right.$ at $\left.20{ }^{\circ} \mathrm{C}\right)$, which is a significant 433 advantage. On the other hand, the boiling point of $\mathrm{NMM}$ is $116^{\circ} \mathrm{C}\left(\mathrm{MDEA} 243{ }^{\circ} \mathrm{C}\right)$. $\mathrm{NMM}$ is 434 thus more volatile than MDEA. The NMM solvent should thus be used at a lower temperature, to 435 minimize the solvent losses. This is e.g. also done in the Rectisol process which uses methanol 436 (boiling point $65^{\circ} \mathrm{C}$ ).

437 The environment, health and safety (EHS) of solvents for $\mathrm{CO}_{2}$ capture is a potential issue. In 438 principle, amine emissions should not be an obstacle because the causes are well known and 439 counter-measures can be put in place (operating temperature and pressure, water wash, Brownian 
440 demister, reclaiming units, etc.). One clear advantage of using physical solvents is that there is

441 much less thermal and oxidative solvent degradation because the regeneration is not thermal and

442 the high operating pressure avoids oxygen ingress. According to the safety datasheet ${ }^{108}$ NMM is

443 flammable, corrosive and harmful, but the substance contains no components considered to be

444 either persistent, bioaccumulative and toxic.

a

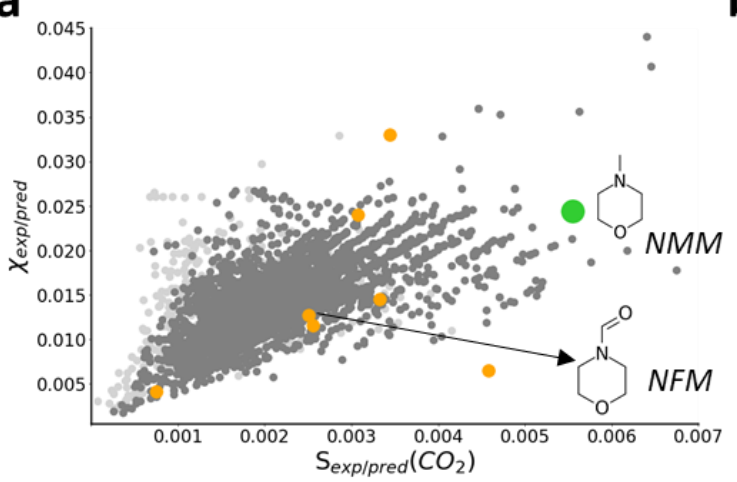

b

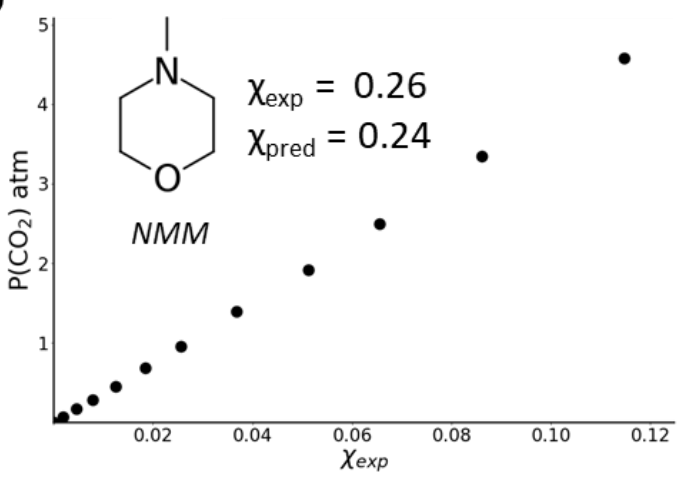

Figure 3. (a) A plot of $\mathrm{CO}_{2}$ molecular fraction values vs Kuenen coefficients. Experimental values - black and

447 orange (solvents used in the industry). (b) Variation of mole fraction with partial pressure for $\mathrm{CO}_{2}$ in $\mathrm{NMM}$ at

$448 \quad 298.15 \mathrm{~K}$ experimentally measured in this paper; $\chi_{\exp }$ - experimental mole fraction value at $1 \mathrm{~atm}$ and $298.15 \mathrm{~K}$, $\chi_{\text {pred }}$

449 - predicted value. Predicted values for compounds inside AD - grey, outside AD - light grey, for NMM - green.

450 The position of the NFM on the plot is shown for comparison.

452 The selectivity of the NMM calculated from predicted mole fraction values is comparable to

453 the one of industrially used solvents (Figure S10). Other tertiary amines were also among the 454 most selective solvents. For example, the 3-(Dimethylamino)-1,2-propanediol was among the 455 most selective solvents for all gases. Among other classes of solvents with the highest selectivity 
456 indexes were cyclic amides (e.g. 5-(hydroxymethyl)-1-methylpyrrolidin-2-one) and ketones (e.g.

457 methoxyacetone).

458 To conclude, the rational approach to the design of new physical solvents based on the usage

459 of machine learning for modeling of structure-solubility relationships was suggested in this

460 paper. The collected data on solubility of gases were used to build QSPR models, which were

461 then applied to identify compounds potentially superior to the existing ones via virtual screening

462 of industrially produced chemicals. We have identified pure tertiary amines with a remarkable

$463 \mathrm{CO}_{2}$ absorption capacity. Previously, the team of Heldebrandt et al. ${ }^{101}$ has investigated the use of

464 pure, anhydrous amines for high pressure $\mathrm{CO}_{2}$ absorption. They compared the performance of

465 anhydrous EDEA to the Fluor solvent (propylene carbonate), to Selexol, and to aqueous MDEA

466 for a representative absorber. Despite the attractiveness due to lower energy consumptions, the

467 use of anhydrous or water-lean amines faces numerous challenges, for example, their lower

468 absorption capacity and their higher viscosity. ${ }^{6}$ In this work we have focused on the gas

469 solubility. A further extension of the chemoinformatics workflow for the prediction of other

470 industrial important solvent properties might be very useful in the identification of the most

471 suitable physical (co-)solvent (optimal absorption properties, selectivity, viscosity, ${ }^{109}$ EHS

472 impact, ${ }^{110}$ etc.) for a given application.

473

474 ASSOCIATED CONTENT

475 Supporting Information.

476 
477 Table S1. Mole fraction solubilities of gases in organic liquid solvents at $298.15 \mathrm{~K}$ and $1 \mathrm{~atm}$.

478 Figure S1. Negative logarithm of mole fraction solubility values distribution.

479 Figure S2. A scheme for building the ISIDA consensus model.

480 Text S1. Description of the experimental protocols.

481 Figure S3a. Schematic diagram of apparatus used to determine gas solubility.

482 Figure S3b. Flow diagram of the synthetic apparatus used to determine gas solubility.

483 Figure S4. A pictorial view of $\mathrm{CO}_{2}$ loading arrangement.

484 Figure S5. Plots of experimental molecular fraction values vs Kuenen coefficients for $\left(\mathrm{CH}_{4}, \mathrm{H}_{2}\right.$, $\left.485 \mathrm{CO}, \mathrm{N}_{2}\right)$.

486 Figure S6. Plots of selectivity indexes based on experimental molecular fraction values vs $\mathrm{CO} 2$ 487 Kuenen coefficients.

488 Table S2. Outliers from ISIDA consensus models.

489 Table S3. Performance estimation for modeling using quantum-chemical descriptors.

490 Figure $\mathrm{S} 7$. Variation of $\mathrm{CO}_{2}$ solubility in several series of structurally similar solvents.

491 Figure S8. Learning curves for machine learning models.Figure S9. Distribution of molecular

492 descriptors for the compounds from the screening library and the learning set.

493 Figure S10. Plots of predicted selectivity indexes vs Kuenen coefficient of $\mathrm{CO}_{2}$. 
495 AUTHOR INFORMATION

\section{Corresponding Author}

497 *Professor Alexandre Varnek. Laboratory of Chemoinformatics, Faculty of Chemistry,

498 University of Strasbourg, 4, Blaise Pascal Str., 67081, Strasbourg, France. email:

499 varnek@unistra.

$500 *$ Doctor Frédérick de Meyer. TotalEnergies S.E., Exploration Production, Development and 501 Support to Operations, Liquefied Natural Gas - Acid Gas Entity, CCUS R\&D Program, Paris,

50292078 France. email: frederick.de-meyer@totalenergies.com.

\section{Author Contributions}

504 The manuscript was written through contributions of all authors. All authors have given approval 505 to the final version of the manuscript.

\section{$506 \quad$ Funding Sources}

507 This work was supported by the Carbon Capture Utilization and Storage (CCUS) transverse

508 R\&D program from TotalEnergies S.E.

509 ACKNOWLEDGMENT

510 The authors are grateful to Dr. Fanny Bonachera for her help with the implementation of

511 models to the Predictor software. The authors sincerely acknowledge the Laboratory for

512 Thermophysical Properties in Oldenburg, Germany, for performing a part of the experimental 513 work.

\section{ABBREVIATIONS}


515 Caroxin D - 1,1,2,2,3,3,4,4-octafluoro-1,4-bis(1,1,1,2,3,3,3-heptafluoropropan-2-yloxy)butane

516 Caroxin F - 1,1,1,2,2,3,3,4,4,5,5,6,6-tridecafluoro-6-(1,1,1,2,3,3,3-heptafluoropropan-2-

517 yloxy)hexane

518 DEG - 2-(2-hydroxyethoxy)ethanol (diethylene glycol)

519 DEGM - 2-(2-Methoxyethoxy)ethan-1-ol (diethylene glycol monomethyl ether)

520 diglyme - 1-methoxy-2-(2-methoxyethoxy)ethane

$521 \quad$ DMF - N,N-dimethylformamide

522 DMI - 1,3-Dimethylimidazolidin-2-one

523 DMSO - methylsulfinylmethane (dimethyl sulfoxide)

524 EG - ethane-1,2-diol (ethylene glycol)

525 glycerol - propane-1,2,3-triol

526 HMPA - N-[bis(dimethylamino)phosphoryl]-N-methylmethanamine (hexametapol)

527 M2CA - methyl 2-cyanoacetate

528 MDEA - 2-[2-hydroxyethyl(methyl)amino]ethanol 2-[ethyl(2-hydroxyethyl)amino]ethanol

529 EDEA - 2-[ethyl(2-hydroxyethyl)amino]ethanol

530 DEAE-EO - 2-[2-(diethylamino)ethoxy]ethanol

531 methoxyacetone - 1-methoxypropan-2-one

532 NMM - 4-methylmorpholine 
533 NFM - morpholine-4-carbaldehyde (N-formylmorpholine)

534 NMP - 1-methylpyrrolidin-2-one

535 PC - 4-methyl-1,3-dioxolan-2-one (propylene carbonate)

536 TDG - 2-(2-hydroxyethylsulfanyl)ethanol (thiodiglycol)

537 pentaglyme - 1-methoxy-2-[2-[2-[2-(2-methoxyethoxy)ethoxy]ethoxy]ethoxy]ethane

538 perflubron - 1-bromo-1,1,2,2,3,3,4,4,5,5,6,6,7,7,8,8,8-heptadecafluorooctane

539 perfluoroheptane $-1,1,1,2,2,3,3,4,4,5,5,6,6,7,7,7$-hexadecafluoroheptane

540 perfluoro(methylcyclohexane) - 1,1,2,2,3,3,4,4,5,5,6-undecafluoro-6-

541 (trifluoromethyl)cyclohexane

542 perfluoroctane - 1,1,1,2,2,3,3,4,4,5,5,6,6,7,7,8,8,8-octadecafluorooctane

543 perfluorotributylamine - 1,1,2,2,3,3,4,4,4-nonafluoro-N,N-bis $(1,1,2,2,3,3,4,4,4$ -

544 nonafluorobutyl)butan-1-amine

545 THF - oxolane (tetrahydrofuran)

$546 \quad$ TPrP - tripropyl phosphate

$547 \chi-$ mole fraction solubility

$548 \quad \mathrm{~S}-$ Kuenen coefficient

549 SI - Kuenen coefficients selectivity index

550 squalane - 2,6,10,15,19,23-hexamethyltetracosane 


\section{REFERENCES}

553 (1) Net Zero by 2050, A Roadmap for the Global Energy Sector, IEA Report, May 2021. 554 https://www.iea.org/reports/Net-Zero-by-2050 (Accessed 17.06.2021).

555 (2) Sifat, N. S.; Haseli, Y. A Critical Review of CO2 Capture Technologies and Prospects for

$556 \quad$ Clean Power Generation. Energies $42019, \quad 12 \quad$ (21), 4143. $557 \quad$ https://doi.org/10.3390/en12214143.

558 (3) Abdulsalam, J.; Mulopo, J.; Amosa, M. K.; Bada, S.; Falcon, R.; Oboirien, B. O. Towards a 559 Cleaner Natural Gas Production: Recent Developments on Purification Technologies. Sep. Sci. Technol. 2019, 54 (15), 2461-2497. https://doi.org/10.1080/01496395.2018.1547761.

561 (4) N.Borhani, T.; Wang, M. Role of Solvents in CO2 Capture Processes: The Review of Selection and Design Methods. Renew. Sustain. Energy Rev. 2019, 114, 109299. https://doi.org/10.1016/j.rser.2019.109299.

564 (5) Wang, X.; Song, C. Carbon Capture From Flue Gas and the Atmosphere: A Perspective. Front. Energy Res. 2020, 8, 560849. https://doi.org/10.3389/fenrg.2020.560849.

566 (6) Wanderley, R. R.; Pinto, D. D. D.; Knuutila, H. K. From Hybrid Solvents to Water-Lean 567 Solvents - A Critical and Historical Review. Sep. Purif. Technol. 2021, 260, 118193. $568 \quad$ https://doi.org/10.1016/j.seppur.2020.118193.

569 (7) Collodi, G.; Azzaro, G.; Ferrari, N.; Santos, S. Techno-Economic Evaluation of Deploying 570 CCS in SMR Based Merchant H2 Production with NG as Feedstock and Fuel. Energy $571 \quad$ Procedia 2017, 114, 2690-2712. https://doi.org/10.1016/j.egypro.2017.03.1533.

572 (8) Yan, Y.; Thanganadar, D.; Clough, P. T.; Mukherjee, S.; Patchigolla, K.; Manovic, V.; 573 Anthony, E. J. Process Simulations of Blue Hydrogen Production by Upgraded Sorption 
Enhanced Steam Methane Reforming (SE-SMR) Processes. Energy Convers. Manag. 2020,

575

576

577

578

579

580

581

582

583

584

585

586

587

588

589

590

591

592

593

594

595

596 222, 113144. https://doi.org/10.1016/j.enconman.2020.113144.

(9) Pirig N. Ya.; Polyuzhin I. V.; Makitra R. G. Carbon Dioxide Solubility. Russ. J. Appl. Chem. 1993, 4 (66), 691-695.

(10) Li, H.; Yan, D.; Zhang, Z.; Lichtfouse, E. Prediction of CO2 Absorption by Physical Solvents Using a Chemoinformatics-Based Machine Learning Model. Environ. Chem. Lett. 2019, 17 (3), 1397-1404. https://doi.org/10.1007/s10311-019-00874-0.

(11) Li, H.; Tang, Z.; He, Z.; Gui, X.; Cui, L.; Mao, X. Structure-Activity Relationship for CO2 Absorbent. Energy 2020, 197, 117166. https://doi.org/10.1016/j.energy.2020.117166.

(12) Shi, W.; Thompson, R. L.; Macala, M. K.; Resnik, K.; Steckel, J. A.; Siefert, N. S.; Hopkinson, D. P. Molecular Simulations of $\mathrm{CO}_{2}$ and $\mathrm{H}_{2}$ Solubility, $\mathrm{CO}_{2}$ Diffusivity, and Solvent Viscosity at $298 \mathrm{~K}$ for 27 Commercially Available Physical Solvents. J. Chem. Eng. Data 2019, 64 (9), 3682-3692. https://doi.org/10.1021/acs.jced.8b01228.

(13) Klamt, A. Conductor-like Screening Model for Real Solvents: A New Approach to the Quantitative Calculation of Solvation Phenomena. J. Phys. Chem. 1995, 99 (7), 2224-2235. https://doi.org/10.1021/j100007a062.

(14) Kim, J.; Maiti, A.; Lin, L.-C.; Stolaroff, J. K.; Smit, B.; Aines, R. D. New Materials for Methane Capture from Dilute and Medium-Concentration Sources. Nat. Commun. 2013, 4 (1), 1694. https://doi.org/10.1038/ncomms2697.

(15) Gorji, A. E.; Gorji, Z. E.; Riahi, S. Quantitative Structure-Property Relationship (QSPR) for Prediction of CO2 Henry's Law Constant in Some Physical Solvents with Consideration of Temperature Effects. Korean J. Chem. Eng. 2017, 34 (5), 1405-1415. https://doi.org/10.1007/s11814-017-0018-0. 
(16) Kode Srl, Dragon (Software for Molecular Descriptor Calculation) Version 7.0.8, 2017, https://chm.kode-solutions.net.

(17) Orlov, A. A.; Marcou, G.; Horvath, D.; Cabodevilla, A. E.; Varnek, A.; Meyer, F. de. Computer-Aided Design of New Physical Solvents for Hydrogen Sulfide Absorption. Ind. Eng. Chem. Res. 2021, 60 (23), 8588-8596. https://doi.org/10.1021/acs.iecr.0c05923.

(18) H. Rostami; Riahi, S. Quantitative Structure-Property Relationship Study on Solubility of Hydrogen Sulfide in Organic Solvent; Kish, Iran, 2014.

(19) Carbon Dioxide in Non-Aqueous Solvents at Pressures Less than $200 \mathrm{KPa}$. In IUPAC Solubility Data Series (Volume 50); Fogg, P. G. T.; Ed.; Pergamon: Amsterdam, 61988; Pp. 1-483, 1992.

(20) Methane. In IUPAC Solubility Data Series (Volume 27/28); Clever, H. L.; Young, C. L.; Eds.; Pergamon: Amsterdam, 61988; Pp 1-783, 1987.

(21) Carbon Monoxide. In IUPAC Solubility Data Series (Volume 43); Cargill, R.W.; Ed; Eds.; Pergamon: Amsterdam, 61988; Pp 1-783, 1990.

(22) Hydrogen and Deuterium. In IUPAC Solubility Data Series (Volume 5/6); Young, C. L.; Ed; Pergamon: Amsterdam, 61988; Pp 1-646, 1981.

(23) Nitrogen and Air. In IUPAC Solubility Data Series (Volume 10); Battino, R; Ed; Pergamon: Amsterdam, 61988; Pp 1-570, 1982.

(24) Décultot, M.; Ledoux, A.; Fournier-Salaün, M.-C.; Estel, L. Solubility of CO2 in Methanol, Ethanol, 1,2-Propanediol and Glycerol from $283.15 \mathrm{~K}$ to $373.15 \mathrm{~K}$ and up to $6.0 \mathrm{MPa}$. $J$. Chem. Thermodyn. 2019, 138, 67-77. https://doi.org/10.1016/j.jct.2019.05.003. 
618 (25) Yamamoto, H.; Kamei, H.; Tokunaga, J. Solubilities of Argon, Oxygen and Nitrogen in 619 1,2-Propanediol + Water Mixed Solvent at $298.15 \mathrm{~K}$ and $101.33 \mathrm{kPa}$. J. Chem. Eng. Japan. $620 \quad 1994,27(4), 455-459$.

621 (26) Li, Y.; Liu, Q.; Huang, W.; Yang, J. Solubilities of CO2 Capture Absorbents Methyl 622 Benzoate, Ethyl Hexanoate and Methyl Heptanoate. J. Chem. Thermodyn. 2018, 127, 25$623 \quad$ 32. https://doi.org/10.1016/j.jct.2018.07.010.

624 (27) Li, X.; Jiang, Y.; Han, G.; Deng, D. Investigation of the Solubilities of Carbon Dioxide in 625 Some Low Volatile Solvents and Their Thermodynamic Properties. J. Chem. Eng. Data 2016, 61 (3), 1254-1261. https://doi.org/10.1021/acs.jced.5b00893.

(28) Henni, A.; Tontiwachwuthikul, P.; Chakma, A. Solubilities of Carbon Dioxide in Polyethylene Glycol Ethers. Can. J. Chem. Eng. 2008, 83 (2), 358-361. https://doi.org/10.1002/cjce.5450830224.

630 (29) Zhao, Z.; Xing, X.; Tang, Z.; Zhao, Y.; Fei, W.; Liang, X.; He, Z.; Zhang, S.; Guo, D. 631 Solubility of $\mathrm{CO} 2$ and $\mathrm{H} 2 \mathrm{~S}$ in Carbonates Solvent: Experiment and Quantum Chemistry Calculation. Int. J. Greenh. Gas Control 2017, 59, 123-135. https://doi.org/10.1016/j.ijggc.2017.02.011.

635 Solvents. J. Chem. Eng. Data 2015, 60 (1), 104-111.

636 (31) Yogish, K. Solubility of CO2 in Some Physical Solvents. J. Chem. Eng. Jpn. 1991, 24 (1), 135-137. https://doi.org/10.1252/jcej.24.135.

(32) Miller, M. B.; Chen, D.-L.; Luebke, D. R.; Johnson, J. K.; Enick, R. M. Critical Assessment 640 of CO2 Solubility in Volatile Solvents at 298.15 K. J. Chem. Eng. Data 2011, 56 (4), 15651572. https://doi.org/10.1021/je101161d. 
641 (33) Hansen, C. M. Hansen Solubility Parameters: A User's Handbook, 2nd ed.; CRC Press: Boca Raton, 2007.

(34) Gennaro, A.; Isse, A. A.; Vianello, E. Solubility and Electrochemical Determination of CO2 in Some Dipolar Aprotic Solvents. J. Electroanal. Chem. Interfacial Electrochem.

(35) Anouti, M.; Dougassa, Y. R.; Tessier, C.; El Ouatani, L.; Jacquemin, J. Low Pressure Carbon Dioxide Solubility in Pure Electrolyte Solvents for Lithium-Ion Batteries as a Function of Temperature. Measurement and Prediction. J. Chem. Thermodyn. 2012, 50, $71-$ 79. https://doi.org/10.1016/j.jct.2012.01.027.

(36) Li, Y.; You, Y.; Huang, W.; Yang, J. Solubility Measurement and Thermodynamic Properties Calculation for Several $\mathrm{CO}_{2}+$ Ether Absorbent Systems. J. Chem. Eng. Data

(37) Li, Y.; Zheng, D.; Dong, L.; Xiong, B. Solubilities of Carbon Dioxide in 2-Methoxyethyl Acetate, 1-Methoxy-2-Propyl Acetate and 3-Methoxybutyl Acetate. J. Chem. Thermodyn. 2014, 74, 126-132. https://doi.org/10.1016/j.jct.2014.01.019.

(38) Li, Y.; Liu, Q.; Huang, W.; Yang, J. Below the Room Temperature Measurements of

(39) Flowers, B. S.; Mittenthal, M. S.; Jenkins, A. H.; Wallace, D. A.; Whitley, J. W.; Dennis,

660 G. P.; Wang, M.; Turner, C. H.; Emel'yanenko, V. N.; Verevkin, S. P.; Bara, J. E. 1,2,3661 Trimethoxypropane: A Glycerol-Derived Physical Solvent for $\mathrm{CO}_{2}$ Absorption. ACS 662 Sustain. Chem. Eng. 2017, 5

$(1)$ 911-921. https://doi.org/10.1021/acssuschemeng.6b02231. 
664 (40) Li, Y.; Huang, W.; Zheng, D.; Mi, Y.; Dong, L. Solubilities of CO2 Capture Absorbents 2665 Ethoxyethyl Ether, 2-Butoxyethyl Acetate and 2-(2-Ethoxyethoxy)Ethyl Acetate. Fluid Phase Equilibria 2014, 370, 1-7. https://doi.org/10.1016/j.fluid.2014.02.029.

667 (41) Schappals, M.; Breug-Nissen, T.; Langenbach, K.; Burger, J.; Hasse, H. Solubility of Carbon Dioxide in Poly(Oxymethylene) Dimethyl Ethers. J Chem Eng Data 2017, 5.

(42) Gui, X.; Tang, Z.; Fei, W. Solubility of CO2 in Alcohols, Glycols, Ethers, and Ketones at High Pressures from (288.15 to 318.15) K. J. Chem. Eng. Data 2011, 56 (5), 2420-2429. https://doi.org/10.1021/je101344v.

(43) Gui, X.; Wang, W.; Wang, C.; Zhang, L.; Yun, Z.; Tang, Z. Vapor-Liquid Phase Equilibrium Data of $\mathrm{CO}_{2}$ in Some Physical Solvents from 285.19 K to 313.26 K. J. Chem. Eng. Data 2014, 59 (3), 844-849. https://doi.org/10.1021/je400985u.

(44) Jou, F.-Y.; Otto, F. D.; Mather, A. E. Solubility of H2S and CO2 in Diethylene Glycol at Elevated Pressures. Fluid Phase Equilibria 2000, $175 \quad$ (1), 53-61. https://doi.org/10.1016/S0378-3812(00)00440-4.

(45) F. Blanchard; B. Carre; F. Bonhomme; P. Biensan; D. Lemordat. Solubility of Carbon Dioxide in Alkylcarbonates and Lactones. Can. J. Chem. No. 81, 385-391.

(46) Wu, F.; Zhao, Q.; Tao, L.; Danaci, D.; Xiao, P.; Hasan, F. A.; Webley, P. A. Solubility of Carbon Monoxide and Hydrogen in Methanol and Methyl Formate: 298-373 K and 0.3-3.3 MPa. J. Chem. Eng. Data 2019, $64 \quad$ (12), 5609-5621. https://doi.org/10.1021/acs.jced.9b00676.

(47) Qureshi, M. S.; Le Nedelec, T.; Guerrero-Amaya, H.; Uusi-Kyyny, P.; Richon, D.; Alopaeus, V. Solubility of Carbon Monoxide in Bio-Oil Compounds. J. Chem. Thermodyn. 2017, 105, 296-311. https://doi.org/10.1016/j.jct.2016.10.030. 
(48) Brunner, E. Solubility of Hydrogen in 10 Organic Solvents at 298.15, 323.15, and 373.15 K. J. Chem. Eng. Data 1985, 30 (3), 269-273. https://doi.org/10.1021/je00041a010.

(49) Brunner, E. Solubility of Hydrogen in Diols and Their Ethers. J. Chem. Thermodyn. 1980, 12 (10), 993-1002. https://doi.org/10.1016/0021-9614(80)90140-8.

(50) Purwanto; Deshpande, R. M.; Chaudhari, R. V.; Delmas, H. Solubility of Hydrogen, Carbon Monoxide, and 1-Octene in Various Solvents and Solvent Mixtures. J. Chem. Eng. Data 1996, 41 (6), 1414-1417. https://doi.org/10.1021/je960024e.

(51) Krüger, M. B.; Selle, C.; Heller, D.; Baumann, W. Determination of Gas Concentrations in Liquids by Nuclear Magnetic Resonance: Hydrogen in Organic Solvents. J. Chem. Eng. Data 2012, 57 (6), 1737-1744. https://doi.org/10.1021/je2013582.

(52) Henni, A.; Tontiwachwuthikul, P.; Chakma, A. Solubility Study of Methane and Ethane in Promising Physical Solvents for Natural Gas Sweetening Operations. J. Chem. Eng. Data 2006, 51 (1), 64-67. https://doi.org/10.1021/je050172h.

(53) Hesse, P. J.; Battino, R.; Scharlin, P.; Wilhelm, E. Solubility of Gases in Liquids. 21. Solubility of $\mathrm{He}, \mathrm{Ne}, \mathrm{Ar}, \mathrm{Kr}, \mathrm{N} 2, \mathrm{O} 2, \mathrm{CH} 4, \mathrm{CF} 4$, and SF6in 2,2,4-Trimethylpentane AtT= $298.15 \quad$ K. J. Chem. Thermodyn. 1999, $31 \quad$ (9), 1175-1181. https://doi.org/10.1006/jcht.1999.0529.

(54) Battino, R.; Rettich, T. R.; Tominaga, T. The Solubility of Nitrogen and Air in Liquids. $J$. Phys. Chem. Ref. Data 1984, 13 (2), 563-600. https://doi.org/10.1063/1.555713.

(55) Bo, S.; Battino, R.; Wilhelm, E. Solubility of Gases in Liquids. 19. Solubility of He, Ne, Ar, $\mathrm{Kr}, \mathrm{Xe}, \mathrm{N} 2, \mathrm{O} 2, \mathrm{CH} 4, \mathrm{CF} 4$, and SF6 in Normal 1-Alkanols n-ClH2l+1OH (1 .Ltoreq. 1 .Ltoreq. 11) at 298.15 K. J. Chem. Eng. Data 1993, 38 (4), 611-616. https://doi.org/10.1021/je00012a035. 
710 (56) Hesse, P. J.; Battino, R.; Scharlin, P.; Wilhelm, E. Solubility of Gases in Liquids. 20.

711 Solubility of $\mathrm{He}, \mathrm{Ne}, \mathrm{Ar}, \mathrm{Kr}, \mathrm{N} 2, \mathrm{O} 2, \mathrm{CH} 4, \mathrm{CF} 4$, and SF6 in n-Alkanes n-ClH21+2 $(6 \leq 1 \leq$

712 16) at $298.15 \quad$ K. J. Chem. Eng. Data 1996, $41 \quad$ (2), $195-201$.

713 https://doi.org/10.1021/je9502455.

714 (57) Pardo, J.; López, M. C.; Santafé, J.; Royo, F. M.; Urieta, J. S. Solubility of Gases in

715 Butanols. I. Solubilities of Nonpolar Gases in 1-Butanol from 263.15 to $303.15 \mathrm{~K}$ at 101.33

716 KPa Partial Pressure of Gas. Fluid Phase Equilibria 1995, 109 (1), 29-37.

717 https://doi.org/10.1016/0378-3812(95)02712-N.

718 (58) Pardo, J.; López, M. C.; Mayoral, J. A.; Royo, F. M.; Urieta, J. S. Solubility of Gases in

719 Butanols. III. Solubilities of Non-Polar Gases in 2-Butanol from 263.15 to $303.15 \mathrm{~K}$ at

720 101.33 KPa Partial Pressure of Gas. Fluid Phase Equilibria 1997, 134 (1-2), 133-140.

721 https://doi.org/10.1016/S0378-3812(97)00064-2.

722 (59) Pardo, J.; López, M. C.; Santafé, J.; Royo, F. M.; Urieta, J. S. Solubility of Gases in

723 Butanols II. Solubilities of Nonpolar Gases in 2-Methyl-1-Propanol from 263.15 to 303.15

724 K at 101.33 KPa Partial Pressure of Gas. Fluid Phase Equilibria 1996, 119 (1), 165-173.

$725 \quad$ https://doi.org/10.1016/0378-3812(95)02984-2.

726 (60) Pardo, J.; Mainar, A. M.; Lopez, M. C.; Royo, F.; Urieta, J. S. Solubility of Gases in

727 Butanols IV. Solubilities of Nonpolar Gases in 2-Methyl-2-Propanol at $303.15 \mathrm{~K}$ and 728 101.33 KPa Partial Pressure of Gas. Fluid Ph. Equilibria. 1999, 155 (1), 127-137.

729 (61) Weng, W.-L.; Chen, J.-T.; Chang, J.-S.; Chang, S.-L. Vapor-Liquid Equilibria for Nitrogen 730 with 2-Hexanol, 2-Heptanol, or 2-Octanol Binary Systems. Fluid Phase Equilibria 2006, 248 (2), 168-173. https://doi.org/10.1016/j.fluid.2006.08.005. 
732 (62) Gallardo, M. A.; Melendo, J. M.; Urieta, J. S.; Losa, C. G. Solubility of Non-Polar Gases in 733 Cyclohexanone between 273.15 and $303.15 \mathrm{~K}$ at 101.32 KPa Partial Pressure of Gas. Can.

(63) Gallardo, M. A.; López, M. C.; Urieta, J. S.; Losa, C. G. Solubility of He, Ne, Ar, Kr, Xe,

(64) Gallardo, M.A.; López, M.C.; Urieta, J.S.; Gutierrez Losa, C. Solubility of 15 non-polar gases (He, Ne, Ar, Kr, Xe, H2, D2, N2, O2, CH4, C2H4, C2H6, CF4, SF6 and CO2) in cycloheptanone. Fluid Ph. Equilibria. 1990, 58 (1-2), 1990, 159-172.

(65) Arai, C; Yoshitama, T.; Nishihara, K.; Sano, Y. Gas Solubilities in Esters of Oleic Acid. Kagaku Kougaku Ronbunsyu 1989, 15 (6), 1193-1195.

(66) Lizano, L. P.; López, M. C.; Royo, F. M.; Urieta, J. S. Solubility of Non Polar Gases in Formaldehyde Diethyl Acetal Between- 10 and $30^{\circ} \mathrm{C}$, and 1 Atm Partial Pressure of Gas. $J$. Solut. Chem. 1990, 19 (7), 721-728. https://doi.org/10.1007/BF00647390.

(67) Urieta, J. S.; Gibanel, F.; Martínez-López, J. F.; Pardo, J. I.; Mainar, A. M. Solubilities of Gases in Cycloethers. The Solubility of 13 Nonpolar Gases in 2,5-Dimethyltetrahydrofuran at 273.15 to $303.15 \mathrm{~K}$ and $101.32 \mathrm{KPa}$. J. Chem. Thermodyn. 2019, 132, 306-315. https://doi.org/10.1016/j.jct.2018.12.037.

(68) Gibanel, F.; López, M. C.; Royo, F. M.; Rodríguez, V.; Urieta, J. S. Solubility of Nonpolar Gases in Tetrahydropyran at 0 to $30^{\circ} \mathrm{C}$ and $101.33 \mathrm{KPa}$ Partial Pressure of Gas. J. Solut. 753 Chem. 1994, 23 (11), 1247-1256. https://doi.org/10.1007/BF00974033. 
754 (69) Gibanel, F.; López, M. C.; Gallardo, M. A.; Urieta, J. S.; Gutiérrez Losa, C. Solubility of 755 Nonpolar Gases in Hexamethylenoxide. Fluid Phase Equilibria 1988, 42, 261-268. 756 https://doi.org/10.1016/0378-3812(88)80063-3.

757 (70) Mainar, A.M.; Pardo, J.; Royo, F.M.; Lopez, M.C.; Urieta, J.S. Solubility of nonpolar gases 758 in 2,2,2-trifluoroethanol at $25 \mathrm{C}$ and $101.33 \mathrm{kPa}$ partial pressure of gas. J. Solution. Chem. $759 \quad 1996,25(6), 589-595$.

760 (71) Lopez, M. C.; Gallardo, M. A.; Urieta, J. S.; Gutierrez Losa, C. Solubility of Nonpolar 761 Gases in Halogenated Compounds. 1. Solubility of Hydrogen, Deuterium, Nitrogen, 762 Oxygen, Methane, Ethylene, Ethane, Carbon Tetrafluoride, Sulfur Hexafluoride and Carbon 763 Dioxide in Chlorocyclohexane at 263.15-303.15 K and 101.32 KPa of Partial Pressure of 764 Gas. J. Chem. Eng. Data 1987, 32 (4), 472-474. https://doi.org/10.1021/je00050a027.

765 (72) Lopez, M. C.; Gallardo, M. A.; Urieta, J. S.; Gutierrez Losa, C. Solubility of Nonpolar 766 Gases in Halogenated Compounds. 2. Solubility of Hydrogen, Deuterium, Nitrogen, 767 Oxygen, Methane, Ethylene, Ethane, Carbon, Tetrafluoride, Sulfur Hexafluoride and 768 Carbon Dioxide in Bromocyclohexane at 263.15- to $303.15 \mathrm{~K}$ and $101.32 \mathrm{KPa}$ Partial 769 Pressure of Gas. J. Chem. Eng. Data 1989, $34 \quad$ (2), 198-200. 770 https://doi.org/10.1021/je00056a015.

771 (73) Nitta, T.; Nakamura, Y.; Ariyasu, H.; Katayama, T. Solubilities of Nitrogen in Binary 772 Solutions of Acetone with Cyclohexane, Benzene, Chloroform and 2-Propanol. J. Chem. 773 Eng. Jpn. 1980, 13 (2), 97-103. https://doi.org/10.1252/jcej.13.97.

774 (74) Akimoto, T.; Nitta, T.; Katayama, T. Nitrogen Solubility and Vapor Pressure of Binary 775 Mixed Solvents Containing Benzene, Carbon Tetrachloride, Cyclohexane and 1-Hexane. J. 776 Chem. Eng. Jpn. 1984, 17 (6), 637-641. https://doi.org/10.1252/jcej.17.637. 
777 (75) Mainar, A. M.; Pardo, J.; García, J. I.; Royo, F. M.; Urieta, J. S. Solubility of Gases in

778 Fluoroorganic Alcohols. J. Chem. Soc. Faraday Trans. 1998, 94 (24), 3595-3599. 779 https://doi.org/10.1039/A807488G.

780 (76) Atlani, M.; Loutaty, R.; Wakselman, C.; Yacono, C. Method of Purifying a Gas Mixture $781 \quad$ Containing Undesirable Gas Compounds. 4504287, March 12, 1985.

782 (77) Barber, R.F.G; Ritter, T.J.; Sweeney, C.W. Removing Sulfur Compounds from Gases. $783 \quad 2245889$ A, January 15, 1992.

784 (78) Gamsjäger, H.; Lorimer, J. W.; Salomon, M.; Shaw, D. G.; Tomkins, R. P. T. The IUPAC785 NIST Solubility Data Series: A Guide to Preparation and Use of Compilations and 786 Evaluations (IUPAC Technical Report). Pure Appl. Chem. 2010, 82 (5), 1137-1159. 787 https://doi.org/10.1351/PAC-REP-09-10-33.

788 (79) KNIME. https://www.knime.com/open-for-innovation-0 (accessed 2021-03 -03).

789 (80) Varnek, A.; Fourches, D.; Hoonakker, F.; Solov'ev, V. P. Substructural Fragments: An 790 Universal Language to Encode Reactions, Molecular and Supramolecular Structures. $J$. 791 Comput. Aided Mol. Des. 2005, 19 (9-10), 693-703. https://doi.org/10.1007/s10822-005$7929008-0$.

793 (81) Varnek, A.; Fourches, D.; Horvath, D.; Klimchuk, O.; Gaudin, C.; Vayer, P.; Solov'ev, V.; 794 Hoonakker, F.; Tetko, I.; Marcou, G. ISIDA - Platform for Virtual Screening Based on 795 Fragment and Pharmacophoric Descriptors. Curr. Comput. Aided-Drug Des. 2008, 4 (3), 796 191-198. https://doi.org/10.2174/157340908785747465.

797 (82) Spartan 18.0; Wavefunction, Inc.:www.wavefun.com.

798 (83) Breiman, L. Random Forests. Mach. Learn. 2001, 45 (1), 5-32. 799 https://doi.org/10.1023/A:1010933404324. 
800

801

802

803

804

805

806

807

808

809

810

811

812

813

814

815

816

817

818

819

820

821

(84) Pedregosa, F.; Varoquaux, G.; Gramfort, A.; Michel, V.; Thirion, B.; Grisel, O.; Blondel, M.; Prettenhofer, P.; Weiss, R.; Dubourg, V.; Vanderplas, J.; Passos, A.; Cournapeau, D.; Brucher, M.; Perrot, M.; Duchesnay, É. Scikit-Learn: Machine Learning in Python. J. Mach. Learn. Res. 2011, 12 (85), 2825-2830.

(85) https://scikit-learn.org/stable/ (accessed 23.10.20).

(86) Chen, T.; Guestrin, C. XGBoost: A Scalable Tree Boosting System. In Proceedings of the 22nd ACM SIGKDD International Conference on Knowledge Discovery and Data Mining; ACM: San Francisco California USA, 2016; pp 785-794. https://doi.org/10.1145/2939672.2939785.

(87) XGBoost, https://xgboost.readthedocs.io/en/latest/python/python_intro.html (accessed 31.05.21).

(88) Cortes, C.; Vapnik, V. Support-Vector Networks. Mach. Learn. 1995, 20 (3), 273-297. https://doi.org/10.1007/BF00994018.

(89) Sahigara, F.; Mansouri, K.; Ballabio, D.; Mauri, A.; Consonni, V.; Todeschini, R. Comparison of Different Approaches to Define the Applicability Domain of QSAR Models. Molecules 2012, 17 (5), 4791-4810. https://doi.org/10.3390/molecules17054791.

(90) Descamps, C.; Coquelet, C.; Bouallou, C.; Richon, D. Solubility of Hydrogen in Methanol at Temperatures from 248.41 to $308.20 \mathrm{~K}$. Thermochim. Acta 2005, 430 (1), 1-7. https://doi.org/10.1016/j.tca.2004.12.001.

(91) Soubeyran, A.; Rouabhi, A.; Coquelet, C. Thermodynamic Analysis of Carbon Dioxide Storage in Salt Caverns to Improve the Power-to-Gas Process. Appl. Energy 2019, 242, 1090-1107. https://doi.org/10.1016/j.apenergy.2019.03.102. 
822 (92) Dicko, M.; Coquelet, C.; Theveneau, P.; Mougin, P. Phase Equilibria of H2S-Hydrocarbons 823 (Propane, n-Butane, and n-Pentane) Binary Systems at Low Temperatures J. Chem. Eng. $824 \quad$ Data 2012, 57, 5, 1534-1543.

825 (93) Cadours, R.; Shah, V.; Weiss, C.; Roquet, D.; Lallemand, F. Industrial Operation of 826 HySWEET ${ }^{\circledR}$, a New Hybrid Solvent for Improved Mercaptan Removal. In Proceedings of 827 the 2nd Annual Gas Processing Symposium; Elsevier, 2010; pp 221-228. 828 https://doi.org/10.1016/S1876-0147(10)02024-0.

829 (94) Skylogianni, E.; Wanderley, R. R.; Austad, S. S.; Knuutila, H. K. Density and Viscosity of 830 the Nonaqueous and Aqueous Mixtures of Methyldiethanolamine and Monoethylene 831 Glycol at Temperatures from 283.15 to 353.15 K. J. Chem. Eng. Data 2019, 64 (12), 5415$832 \quad$ 5431. https://doi.org/10.1021/acs.jced.9b00607.

833 (95) Heldebrant, D. J.; Koech, P. K.; Glezakou, V.-A.; Rousseau, R.; Malhotra, D.; Cantu, D. C. 834 Water-Lean Solvents for Post-Combustion $\mathrm{CO}_{2}$ Capture: Fundamentals, Uncertainties, 835 Opportunities, and Outlook. Chem. Rev. 2017, 117 (14), 9594-9624. 836 https://doi.org/10.1021/acs.chemrev.6b00768.

837 (96) Zheng, R. F.; Barpaga, D.; Mathias, P. M.; Malhotra, D.; Koech, P. K.; Jiang, Y.; Bhakta, 838 M.; Lail, M.; V. Rayer, A.; Whyatt, G. A.; Freeman, C. J.; Zwoster, A. J.; Weitz, K. K.; 839 Heldebrant, D. J. A Single-Component Water-Lean Post-Combustion $\mathrm{CO}_{2}$ Capture Solvent 840 with Exceptionally Low Operational Heat and Total Costs of Capture - Comprehensive 841 Experimental and Theoretical Evaluation. Energy Environ. Sci. 2020, 13 (11), 4106-4113. 842 https://doi.org/10.1039/D0EE02585B. 
843 (97) Vahidi, M.; Shokouhi, M. Experimental Solubility of Carbon Dioxide and Hydrogen 844 Sulfide in 2,2'-Thiodiglycol. J. Chem. Thermodyn. 2019, 133, 202-207. $845 \quad$ https://doi.org/10.1016/j.jct.2019.02.024.

846 (98) Versteeg, G. F.; van Swaaij, W. P. M. On the Kinetics between CO2 and Alkanolamines 847 Both in Aqueous and Non-Aqueous Solutions-II. Tertiary Amines. Chem. Eng. Sci. 1988,

(99) Versteeg, G. F.; van Swaaij, W. P. M. On the Kinetics between CO2 and Alkanolamines Both in Aqueous and Non-Aqueous Solutions-I. Primary and Secondary Amines. Chem. Eng. Sci. 1988, 43 (3), 573-585. https://doi.org/10.1016/0009-2509(88)87017-9.

852 (100) Maddox, R. N.; Mains, G. J.; Rahman, M. A. Reactions of Carbon Dioxide and Hydrogen 853 Sulfide with Some Alkanolamines. Ind. Eng. Chem. Res. 1987, 26 (1), 27-31. https://doi.org/10.1021/ie00061a006.

855 (101) Rainbolt, J. E.; Koech, P. K.; Yonker, C. R.; Zheng, F.; Main, D.; Weaver, M. L.; 856 Linehan, J. C.; Heldebrant, D. J. Anhydrous Tertiary Alkanolamines as Hybrid Chemical and Physical CO2 Capture Reagents with Pressure-Swing Regeneration. Energy Environ. Sci. 2011, 4 (2), 480-484. https://doi.org/10.1039/C0EE00506A.

860 Freeman, C. J.; Heldebrant, D. J. Assessing Anhydrous Tertiary Alkanolamines for High861 Pressure Gas Purifications. Ind. Eng. Chem. Res. 2013, 52 (49), 17562-17572. 862 https://doi.org/10.1021/ie4020974.

863 (103) Battino, R.; Clever, H. L. The Solubility of Gases in Liquids. Chem. Rev. 1966, 66 (4), 864 395-463. https://doi.org/10.1021/cr60242a003. 
865 (104) Pierotti, R. A. A Scaled Particle Theory of Aqueous and Nonaqueous Solutions. Chem. 866 Rev. 1976, 76 (6), 717-726. https://doi.org/10.1021/cr60304a002.

867 (105) Abboud, J.-L. M.; Notari, R. Critical Compilation of Scales of Solvent Parameters. Part I. 868 Pure, Non-Hydrogen Bond Donor Solvents. Pure Appl. Chem. 1999, 71 (4), 645-718. 869 https://doi.org/10.1351/pac199971040645.

870 (106) Lewis, M.; Wu, Z.; Glaser, R. Polarizabilities of Carbon Dioxide and Carbodiimide. 871 Assessment of Theoretical Model Dependencies on Dipole Polarizabilities and Dipole 872 Polarizability Anisotropies. J. Phys. Chem. A 2000, 104 (48), 11355-11361. 873 https://doi.org/10.1021/jp002927r.

874 (107) Zeng, W.; Du, Y.; Xue, Y.; Frisch, H. L. Solubility Parameters. In Physical Properties of 875 Polymers Handbook; Mark, J. E., Ed.; Springer New York: New York, NY, 2007; pp 289876 303. https://doi.org/10.1007/978-0-387-69002-5_16.

877 (108) Sigma-Aldrich Catalog, https://www.sigmaaldrich.com/FR/En/Sds/Aldrich/M56557 $878 \quad$ (Accessed 11.08.21).

879 (109) Kauffman, G. W.; Jurs, P. C. Prediction of Surface Tension, Viscosity, and Thermal 880 Conductivity for Common Organic Solvents Using Quantitative Structure-Property 881 Relationships. J. Chem. Inf. Comput. Sci. 2001, 41 (2), 408-418. 882 https://doi.org/10.1021/ci000139t.

883 (110) Singh, A. K.; Bilal, M.; Iqbal, H. M. N.; Raj, A. Trends in Predictive Biodegradation for 884 Sustainable Mitigation of Environmental Pollutants: Recent Progress and Future Outlook. 885 Sci. Total Environ. 2021, 770, 144561. https://doi.org/10.1016/j.scitotenv.2020.144561. 